\title{
Investigating the Effect of Using Educational Podcasts on Listening Comprehension of Language Learners
}

DOI: https://doi.org/10.47175/rielsj.v1i1.35

\section{| Mohsen Fardavoodi ${ }^{1}$ | Salah Ismaili Gojar ${ }^{1}$ | Morteza Bakhtiarvand ${ }^{1, *}$ | | Leila Khedri Lilves ${ }^{2}$ |}

\author{
${ }^{1}$ Department of Educational \\ Technology, Faculty of \\ Psychology and Education, \\ Allameh Tabataba'i \\ University, Iran \\ ${ }^{2}$ Kharazmi University, Tehran, \\ Iran \\ ${ }^{*}$ Corresponding Email: \\ m_bakhtiarvand@yahoo.com
}

\begin{abstract}
The aim of this study was to investigate the effect of using educational podcasts on listening comprehension of male language learners in Tehran. The statistical population of the present study consisted of all male language learners of Tehran language colleges who were studying in the academic year 20202019. The present study sample consisted of two target languages that were selected purposefully. There were 60 samples, of which 30 were in the control group and 30 in the experimental group. The type of research was quantitative and quasi-experimental with pre-test-post-test design with control group. To understand the required data, a researcher-made audit comprehension test was used. It was used to analyze the obtained data using SPSS software. The results showed that the use of educational podcasts is significantly more effective in increasing the listening comprehension skills of language learners of language schools $F=165 / 001$ than the usual method. Based on the results, it is recommended to use educational podcasts in teaching audio-visual comprehension of learners, which is one of the main problems in language teaching.

KEYWORDS

Podcast; teaching; English Language; Listening Comprehension.
\end{abstract}

\section{INTRODUCTION}

The emergence of innovative technological tools in recent decades has led to an improvement in the teaching process, so that global attitudes toward the teaching and learning process have changed dramatically. In recent years, many believe that students' minds are like empty containers. It is waiting to be filled with knowledge and information, but it has shown great phenomena such as the explosion of information and the increasing spread of technology and its influence on all human dimensions, recent developments in educational sciences and methods of promoting and teaching science. Given the necessity of time, all students must live in a complex society today. The advanced ones that are closely related to scientific and technological issues should be prepared (Harlen, 1999). One of the active methods that has attracted the attention of many education specialists today and in the field of research, its potential importance has been well revealed is the use of construction theory in education and learning (Amani Tehrani, 2001).

Studies show that using modern technology and actively engaging students in the process of teaching and learning allows learners to learn faster and perform better and feel more satisfied with their learning (Omidi and Colleagues, 2011). Significant advances in education are due to new information and communication technologies (Shark, 2010). The development and expansion of the Internet has created new approaches for educators to communicate with learners (Evans, 2008). One of these new technologies which have 
recently received a lot of attention in the field of education is podcasting (Rahimi and Asadollahi, 2011).

A podcast is a form of mobile learning in which a device is used to listen to or view an audio or video program. Apps are placed on the Internet and automatically downloaded to a computer desktop or laptop. The learner can choose the time, place, and how to hear or see them (Evans, 2008). The podcast is also a powerful and complementary tool for popular educational resources, and not an alternative to them and the constant communication between teachers and learners, it also increases learners' motivation. The most important advantage of Podcast is that it can be accessed on mobile phones, portable devices such as iPads and other tablets and computers, and even all my players. P. Terry aired (Fernandez, 2009). Podcasting is a way to create and publish audio and video files on the World Wide Web as a collection of shared themes and themes (Manj, 2005). Although sharing audio and video files on the World Wide Web has been possible since the previous decade, podcasting has entered educational technology as a new approach since 2004 (Skira, 2005). This technology has the inherent potential to improve the quality of teaching experiences and practices and increase learning efficiency (Briggs, 2006).

Today, the use of podcast training has come to the aid of educational systems and has been used as a good teaching aid tool, especially those educational systems that do not see education as limited to the hard walls of classrooms and try to circle Take education beyond the walls of school. Some users consider the availability and ease of content production to be the most important advantage of podcasts, while others point to its biggest weakness, which is the low number of low-quality audio files (Kowsari, 2008). Looking at the history of new information and communication technologies on the Internet, virtual education and multimedia media with attractive and diverse capabilities, we find that the use of these media in educational and training issues, has often had positive consequences so that, The capabilities of the podcast have revived this hope in the hearts of those in charge of education and the education system, which can be used in formal and non-formal education and in specialized and professional groups of youth and adolescents, engineers, doctors and groups. Special physical devices, especially for the blind, should be used as a force lever (Omidi et al., 2011).

As a dynamic and potentially educational paradigm, podcasts can improve teaching and learning in the classroom. Simplicity and convenience, saving time (Obanon et al., 2011), the ability to use at any time and place are other important benefits of podcasts for learners (Evans, 2008; Fernandez, 2009). In addition to the theoretical foundations of multimedia, empirical research on the capabilities of podcasts in education also shows that podcasts have been effective on various dimensions such as: learning and academic achievement of learners (Rahimi and Asadollahi, 2011). Podcasts also increase motivation in learners (Fernandez et al., 2009) and are powerful tools that can be used as a complementary tool in addition to conventional training (Fernandez, 2009). Also, the results of Watter and Blaser's study (2009) showed that most students find the use of podcasts in homework enjoyable and consider this technology as a useful tool for learning. In addition, Dahl (2007) concluded in his study that podcasts should not be used as an alternative to teacherstudent interaction, but rather as an interactive tool for enhancing students' learning experiences (Dahl, 2007).

It also studies (Fernandez et al., 2009; Rahimi and Asadollahi, 2010; Dilio Ianan et al., 2011; Popova and Idrissingha, 2010) on the capabilities of podcasts in education show that the use of various forms of new technologies, multimedia and podcasts affect the learning and academic achievement of learners, and lead to a deeper understanding of learning in learners. 
In another study conducted by Mehdizadeh et al. (2013), to compare the effect of podcast with participatory method in comparison with common method (teacher lecture and group discussion) on the amount of learning and learning (long-term learning) of students in the field of biology An environment was discussed. The results of data covariance analysis showed that the type of teaching method was significantly effective in the amount of learning and learning of students in the field of environmental issues. Thus, the average learning and learning of students in the experimental group (podcast group) was significantly higher than the students in the control group (common method). Also, the accuracy of ETA coefficients showed that the use of participatory podcasting as an educational method in the field of environmental education, explained 31 and $40 \%$ of learning and learning (delayed learning, respectively). Since one of the main problems for learners is their hearing comprehension, on the other hand, listening skills are one of the four main skills of learning English, so the problem is: the impact of using English language teaching podcast on students' hearing comprehension. Son of language schools in Tehran.

\section{METHOD}

The present study was conducted using a two-group semi-experimental design with pretest and post-test and with the aim of investigating the effect of using English language teaching podcast on auditory comprehension of male language learners in Tehran.

\section{Society, sample and sampling method}

The statistical population included all students of language schools in Tehran who were selected as a sample using simple random sampling method and 80 language learners were selected and randomly divided into two experimental and control groups. First, both groups were pre-tested to control the scores of the two groups, and then the learners of the two groups were taught in 10 sessions (control group using common classroom methods and experimental group through English language podcast). . Then, both groups were retested and the results were compared and concluded.

\section{Measuring tools}

The instrument used in this study was a researcher of the English language test. The validity of this test was confirmed by three language teachers. With the implementation of a preliminary test, the Cronbach's alpha test obtained the reliability of the whole test in the preliminary stage with 38 questions of 0.92 , which was appropriate and acceptable.

\section{Data analysis method}

The statistical methods used in this study included the inferential statistical method. In order to generalize the sample attributes to the community, the independent group t test was used to test the research hypothesis. SPSS software was used to describe and analyze the data.

\section{RESULT AND DISCUSSION}

After performing the post-test, the obtained scores were analyzed using SPSS software, the results of which are given below.

Table 1 (1) shows the T-test results of the independent groups for comparing the English language course scores of the two control and experimental groups in the pretest stage. 
Table 1. T-test results of independent groups to compare the English language scores of the control and experimental group in the pre-test stage

\begin{tabular}{llllllll}
\hline $\begin{array}{l}\text { Significance } \\
\text { level }\end{array}$ & $\begin{array}{l}\text { Degree of } \\
\text { freedom }\end{array}$ & $\begin{array}{l}\text { The } \\
\text { amount } \\
\text { of T }\end{array}$ & $\begin{array}{l}\text { Standard } \\
\text { deviation }\end{array}$ & Average & Number Group & Index \\
\hline $0 / 454$ & 116 & $1 / 338$ & $2 / 27$ & $13 / 66$ & 40 & Control & Achievement \\
\cline { 3 - 6 } & & & $2 / 16$ & $13 / 12$ & 40 & $\begin{array}{l}\text { the } \\
\text { experiment }\end{array}$ \\
\hline
\end{tabular}

As shown in Table 3, given that the significance level (0.4455) is higher than 0.05 , the mean scores of the English language course of both control and experimental groups at the pre-test stage are not significantly different.

Table 1 (1) shows the T-test results of the independent groups for comparing the English language course scores of the two control and experimental groups in the pretest stage.

Table 2. T-test results of independent groups to compare the English language scores of the control and experimental group in the post-test stage

\begin{tabular}{llllllll}
\hline $\begin{array}{l}\text { Signifi- } \\
\text { cance } \\
\text { level }\end{array}$ & $\begin{array}{l}\text { Degree } \\
\text { of } \\
\text { freedom }\end{array}$ & $\begin{array}{l}\text { The } \\
\text { amount } \\
\text { of t }\end{array}$ & $\begin{array}{l}\text { Standard } \\
\text { deviation }\end{array}$ & Average & Number & Group & Index \\
\hline $0 / 000$ & 116 & $-16 / 636$ & $1 / 98$ & $14 / 03$ & 40 & Control & Achievement \\
\cline { 4 - 6 } & & & $1 / 53$ & $18 / 41$ & 40 & $\begin{array}{l}\text { the } \\
\text { experiment }\end{array}$ \\
\hline
\end{tabular}

As shown in Table (2), given that the significance level (0.000) is less than 0.05 , it can be said that the average scores of the English language course of both control and experimental groups in the post-test stage together. There is a significant difference. The average scores of respondents who have been trained using podcasts are higher than those who have been trained using common classroom methods.

\section{CONCLUSSION}

From the result and discussion above the researcher can conclude that new forms of communication have brought about major changes in human life. The Internet, which is one of the main tools for changing communication methods, has affected human life. The use of new methods and educational technologies has an effective role in creating a suitable learning environment and educational efficiency. Podcast is one of the newest technologies for producing and publishing audio content on the Internet. Podcasts are one of the new technologies based on the Internet, a medium that can provide scientific, educational, specialized and entertainment services. The aim of this study was to investigate the effect of the use of educational podcasts on the listening comprehension of language learners. Research has shown that the use of educational podcasts has a positive effect on students' language comprehension. The results of this study with studies area conducted by Fernandez et al., (2009); Rahimi and Asadollahi, (2010); Dilio Ian et al. (2011); Popova and Idrissingha (2010), Nouri et al. And colleagues (2013) align.

In general, according to the results, the use of podcasts has a positive effect on teaching and can be used as a suitable learning tool in teaching English. Using podcasts in education requires educators to be familiar with the technology so that they can come up with a good 
plan and strategy for using this tool in teaching, as well as provide the right software and hardware infrastructure. To achieve this, training courses can be held in the field of podcasting. This technology has great potential to improve the quality of educational experiences and increase learning. Due to the relatively high impact of using podcasts, it is recommended that languages promote the culture of using this technology. Podcasting has the ability to archive professors' teaching sessions and distribute them for re-reading. It can provide additional educational materials and be used to transfer to students and other interested parties, or it can require students to produce and present their own educational podcasts as a homework assignment. Creating the right content for podcasts is the hardest and most time consuming part of the process, which includes designing, writing, audiovideo recording, editing digital content, and compressing it. In summary, although the use of podcasts by language schools has become commonplace and seems to improve educational performance, it requires extensive and in-depth research and review of research.

\section{REFERENCES}

Amani Tehrani, Mahmoud. (1380). the spectral view, not the polar view, in the method of teaching-learning experimental sciences based on the new science education plan. The growth of primary education. Journal of Science Education.

Bollinger, D. U., Supanakorn, S., \& Boggs, C.H. (2010). Impact of podcasting on student motivation in the online learning environment. Computers \& Education, 55, 714-722.

Briggs L. (2006). Students take to podcasts. In: Campus Technology Smart Technology Newsletter [Internet]. Available from: http://www.campus-technology.com/ news_article.asp?

Dale, C. (2007). Strategies for using podcasting to support student learning. Journal of Hospitality, Leisure, Sport and Tourism Education, 6(1), 50-57.

Evans, C. (2008). The effectiveness of m-learning in the form of podcast revision lectures in higher education. Computers \& Education, 50, 491-498.

Evans, C. (2008). The effectiveness of m-learning in the form of podcast revision lectures in higher education. Computers \& Education, 50, 491-498.

Fernandez, V. Simo, P. Salon, J. M. (2009). Podcasting: A new technological tool to facilitate good practice in higher education Computer \& Education, 53, 385-392.

Harlan, W. (1999) Effective Teaching of Science. Edinburgh: Scottish Council for Research in Education Id=17593\&typeid=156.

Köse, U. (2010). A blended learning model supported with Web 2.0 technologies. Procedia Social and Behavior Sciences, 2, 2794-2802.

Kowsari, Massoud. (1387). Podcast, particle and public arena. Podcast and Future Radio article collection. Tehran: Radio Research

Mehdizadeh, Hossein; Omidi, Nouria; Azizi, Maryam and Islampanah, Maryam. (1392). the podcast and its impact on the environmental awareness of middle school students. Quarterly Journal of Information and Communication Technology in Educational Sciences. Volumes 2, 2 (consecutive 14), pp. 5-20

Meng P. (2005). Podcasting and Podcasting: A white paper. Missouri: IAT services, The University of Missouri [Internet] Available from: ttp://www.wssa.net/WSSA/SocietyInfo/

O’Bannon, B. W., Lubke, J. K., Beard, J. L., \& Britt, V. G. (2011). Using podcasts to replace lecture: Effect on student achievement. Computer \& Education, 57, 1885-1892.

Popova, A. Edirisingha, P. (2010). How can podcast engaging students in learning activities? Procedia Social Behavioral Sciences, 2, 5034-5038. 
Rahimi, M. \& Asadollahi, F. (2011). Iranian students' readiness for using podcasting in higher education: Access, familiarity, and experience, Procedia Computer Science 3, 197-202 (in English)

Shahbandi, Masoumeh. (1387). Radio podcast and future. Tehran: Sound Research and Development

Skira D J. (2005. podcast. Nursing Education Perspectives. 2006; 27(1) 54-55.

Technology Newsletter [Internet]. Available from: http://www.campus-technology.com/ news_article.asp? Id=17593\&typeid=156

Vatovec, C., \& Balser, T. (2009). Podcasts as tools in introductory environmental studies. Journal of Microbiology \& Biology Education, 10, 19-24. 